\title{
Evaluation of QuEChERS Method for GC Analysis of Pesticides in Tropical Fruits from Yucatan, Mexico
}

\author{
Jocelyn María Coello-Villanueva, Pablo Oscar Martín Acereto-Escoffié, Jesús Alberto Barrón-Zambrano, \\ David Muñoz-Rodríguez*
}

Cuerpo Académico de Química Fundamental y Aplicada, Facultad de Ingeniería Química, Universidad Autónoma de Yucatán, Periférico Norte km. 33.5, Tablaje catastral 13615, Colonia Chuburná de Hidalgo Inn, C.P. 97203, Mérida, Yucatán, México Dr. David Muñoz-Rodríguez, david.mr@correo.uady.mx, +52 (999) 9-46-09-56, 9-46-09-89.

Received May $3^{\text {rd }}, 2017$; Accepted July $1^{\text {st }}, 2017$

\begin{abstract}
The pesticides intake causes health problems; therefore, food must not exceed the maximum allowable limits. The aim of this work was the evaluation of a multi-residue method for the determination of eleven pesticides in tropical fruits of Yucatan, Mexico. Pesticide extraction was carried out with acetonitrile and clean-up by dispersive solid phase extraction (QuEChERS method). The extracts were analyzed by GC/MS. The quantification was performed by the external standard matrix match calibration. Most of the quantification

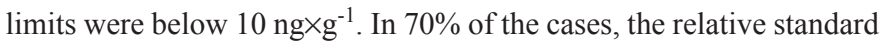
deviation was lower than $15 \%$. The pesticide recoveries ranged from $67.74 \%$ to $138.57 \%$. The method allowed the quantification of pesticides in papaya, melon, dragon fruit and sugar apple.

Keywords: Gas chromatography; QuEChERS; multiresidue analysis; pesticides; tropical fruits
\end{abstract}

\section{Introduction}

The excessive use of pesticides for agricultural purposes has led to various social and environmental concerns [1]. Foods, especially fruits and vegetables, must pass strict regulations for consumption and marketing, mainly for export purposes. The amount of pesticides in food should not exceed the maximum residue limits (MRLs) [2]. The current trend, in the development of analytical methods for the determination of pesticides, is the implementation of multiresidue methods for the analysis of both, pesticides and their degradation products [3]. The methods developed in different countries respond to regional and local needs. Consequently, the analytical range varies among the developed methods in different countries both, with respect to pesticides included and the analytical methods used [4]. This depends on the technological capabilities available and local needs which must be answered.

The QuEChERS (Quick, Easy, Cheap, Efficient, Rugged and Safe) procedure reduces the analytical error due to the application of few steps in the pesticide multiresidue analysis in foods [5]. The procedure is based on the pesticide extraction with acetonitrile, salt addition and purification of the extract through dispersive solid phase extraction
Resumen: La ingesta de plaguicidas causa problemas de salud; por lo tanto, los alimentos no deben exceeder los límites máximos permitidos. El objetivo de este trabajo fue evaluar un método multiresíduo para la determinación de once plaguicidas en frutas tropicales del estado de Yucatán, México. La extracción de plaguicicas se realizó con acetonitrilo y la limpieza por extracción por fase sólida dispersiva (método QuEChERS). Los extractos se analizaron por GC/MS. La cuantificación se realizó por calibración externa utilizando la misma matriz de los extractos. La mayoría de los límites de cuantificación estuvieron por debajo de $1010 \mathrm{ng} \times \mathrm{g}^{-1}$. En el 70\% de los casos la desviación estándar relativa fue menor al 15\%. Las recuperaciones de los plaguicidas estuvieron entre $67.74 \%$ y $138.57 \%$. El método permitió la cuantificación de plaguicidas en papaya, melón, pitaya y saramuyo. Palabras clave: Cromatografía de gases; QuEChERS; análisis multiresíduos; plaguicidas; frutas tropicales

(d-SPE). Finally, the extracts obtained are analyzed by gas or liquid chromatography coupled to mass spectrometry. The different QuEChERS approaches have been widely applied for the multi-class pesticide analysis in fruits and vegetables [6]. Good recoveries have been obtained for most of the pesticides with these approaches with only slight differences among them. However, Lehotay and Maótovská [7] reported that low recoveries of some $\mathrm{pH}$ sensitive analytes prompted the need for a buffering medium. The result of the application of sodium acetate in response to this need increased recoveries remarkably and led to the adoption of the official methods AOAC 2007.01. Lehotay and co-workers [8] stated that there is no need to optimize the QuEChERS method for one particular class of analytes o matrix. In 2015, González-Curbelo and coworkers [6], mentioned that the AOAC 2007.01 method have been adopted as a routine method in many laboratories although many other modified versions have also been developed.

The QuEChERS approach has been applied for the extraction of pesticides from widespread fruits like peaches, strawberries, grapes, lemon, bananas, apples, peaches, kiwi, pear, plum and apricot [9-14]. Furthermore, it has been employed as analytical tool for the analysis of regional fruits [12]. 
In particular, papaya, melon, dragon fruit and sugar apple are typical fruits of Yucatan, Mexico. These fruits have an exotic character and taste recognized by local and foreign consumers. However, different pesticide families are applied as common farming practices.

Parathion-methyl, diazinon, endosulfan, and malathion, are among the typical pesticides used by Yucatecan horticulturists [15]. Malathion and cypermethrin are recommended for the control of pests in papaya crops [16]. Diazinon and parathion-methyl insecticides are commonly used in Mexico and found in papaya maradol [17]. Endosulfan sulfate and malaoxon are degradation products of endosulfan and malathion, respectively. Dichlorvos, chlorothalonil, $\alpha$-endosulfan, $\beta$-endosulfan and coumaphos were chosen on the basis that various local agricultural product distributors reported the widespread use of these pesticides in the region.

There are scarce works based on the QuEChERS method reporting results of pesticides in papaya and melon [13, 18-21]. Besides, the results issued do not cover all the major pesticides used in the state of Yucatan, Mexico for cultivation of melon (malaoxon and coumaphos) and papaya (malaoxon, coumaphos, cypermethrin, dichlorvos). Furthermore, to our knowledge, no records on the evaluation of the pesticides, used in the State of Yucatan, by QuEChERS method and its matrix effect in dragon fruit and sugar apple have been reported.

This paper describes the evaluation of the extraction efficiency of the QuEChERS AOAC Official Method 2007.01 and the matrix effect in the extraction of eleven pesticide residues from papaya, melon, sugar apple and dragon fruit which are typical fruits of Yucatan, Mexico. The matrix effect was evaluated for each pesticide in each fruit and analytical parameters were determined to ensure the reliability of the method using GC-SQ/MS system. A short field survey was conducted with samples grown in four municipalities of the state of Yucatan, Mexico. The results were compared with MRLs established by the European Union.

\section{Material and Methods}

\section{Reagents}

Anhydrous sodium acetate $(99,0 \%)$ and $\mathrm{MgSO}_{4}(99,5 \%)$ together with most reference standards: coumaphos $(99,4 \%)$, chlorothalonil (99.3\%), cypermethrin $(95,1 \%)$, dichlorvos $(99,9 \%), \alpha$-endosulfan $(99,6 \%), \beta$-endosulfan $(99,8 \%)$, endosulfan sulfate $(98,8 \%)$, malaoxon $(95,2 \%)$, malathion $(96,1 \%)$, parathion-methyl $(99,8 \%)$ were purchased from Sigma-Aldrich (Saint Louis, USA).

Diazinon $(99,9 \%)$ and PSA bonded silica were purchased from Supelco (Bellefonte, PA, USA). Acetonitrile for pesticide residue analysis (Pestanal 99,8 \%) and glacial acetic acid $(99,7 \%)$ were obtained from J.T. Baker (Phillipsburg, NJ, USA) and pestanal grade toluene was bought from Riedel-de Haen (C.O.O. Germany).

\section{Samples}

Samples of maradol papaya, melon, dragon fruit, and sugar apple were acquired in local markets of the city of Merida, Yucatan, Mexico. The fruits were previously analyzed by GC/MS and those which yielded SIM chromatograms without peaks of analytes were considered free of pesticides. Pesticide-free samples were used for the preparation of matrix matched calibration solutions (MMCS) and the evaluation of pesticide recoveries.

\section{Sample preparation}

Samples did not undergo any cleaning process. Whole samples, except seeds, in papaya, melon and sugar apple were processed and analyzed in triplicate. Fruit samples, were frozen at $-20^{\circ} \mathrm{C}$ for three days, thawed, cut into small pieces and homogenized with a food processor. The homogenized samples were separated into subsamples of $200 \mathrm{~g}$ and stored in a freezer again.

\section{Preparation of standard solutions}

The stock solutions of each pesticide were prepared in toluene at $20,000 \mathrm{ng} \times \mathrm{mL}^{-1}$ and stored in ambar vials at $-10^{\circ} \mathrm{C}$. The stock solution was used to prepare calibration solutions in toluene at 5, 50, 200500 and $800 \mathrm{ng} \times \mathrm{mL}^{-1}$.

To minimize the matrix effect ([22], [23]), MMCS were prepared for each type of fruit. First, six extracts of each type of fruit were obtained from free pesticide fruits by the QuEChERS method. Then, the extracts were pooled and used to dilute the appropriated volume of the stock solutions to obtain calibration solutions from 5 to $800 \mathrm{ng} \times \mathrm{mL}^{-1}$ (equivalent to 1.25 to $200 \mathrm{ng} / \mathrm{g}$ of pesticide per gram of sample in final extract). MMCS solutions were prepared as needed.

\section{Pesticides extraction by QuEChERS}

A mass of $15 \pm 0.1 \mathrm{~g}$ of sample was weighed in $50 \mathrm{~mL}$ teflon centrifuge tubes. A volume of $15 \mathrm{~mL}$ of acetonitrile with $1 \%$ acetic acid, $6 \mathrm{~g}$ of $\mathrm{MgSO}_{4}$ and $1.5 \mathrm{~g}$ of anhydrous sodium acetate were added to centrifuge tubes which were then capped tightly. The tubes were shaken vigorously by hand $(1 \mathrm{~min})$, making sure that the solvent interacted well with the entire sample and that the crystalline agglomerates broke during agitation. The tubes were centrifuged $(1 \mathrm{~min})$ at $3500 \mathrm{rpm}$. A volume of $8 \mathrm{~mL}$ of acetonitrile extract (upper layer) were transferred to 15 $\mathrm{mL}$ tubes that contained $400 \mathrm{mg}$ of PSA adsorbent and $1200 \mathrm{mg}$ of magnesium sulfate. Tubes were capped and shaken by hand for 30 seconds or using a Vortex. The tubes were centrifuged at $3500 \mathrm{rpm}$ for $1 \mathrm{~min}$. A volume of $4 \mathrm{~mL}$ of acetonitrile extract was transferred to another new $15 \mathrm{~mL}$ graduated centrifuge tubes and $1 \mathrm{~mL}$ of toluene was added. Extracts were evaporated using a nitrogen stream to a volume of approximately $0.5 \mathrm{~mL}$. The volume was taken to $1.0 \mathrm{~mL}$ with toluene. A mass of 0.10 $\mathrm{g}$ of $\mathrm{MgSO}_{4}$ was added and stirred. The tubes were centrifuged (1 min) at $3500 \mathrm{rpm}$ and volumes of 0.2 to $0.5 \mathrm{~mL}$ of the final extracts were transferred to vials for analysis by GC/MS. 


\section{Chromatographic Analysis by GC/MS}

An Agilent Technologies (6890) gas chromatograph system equipped with a series injector (7686) and coupled to mass spectrometer $(5973 \mathrm{~N})$ was used. Compounds were separated on an Equity capillary column $(30 \mathrm{~m}, 0.25 \mathrm{~mm}$ ID and $0.25 \mu \mathrm{m}$ film thickness of 5\%-phenyl-polydimethylsiloxane, Supelco). The carrier gas was $\mathrm{He}$ with a flow rate of $1 \mathrm{~mL} \times \mathrm{min}^{-1}$. The injections $(2 \mu \mathrm{L})$ were carried out in the splitless mode at an inlet temperature of $250^{\circ} \mathrm{C}$. The temperature program started at $100^{\circ} \mathrm{C}$ and rose to $150^{\circ} \mathrm{C}$ at a rate of $25^{\circ} \mathrm{C} \times \mathrm{min}^{-1}$. At $150^{\circ} \mathrm{C}$, the rate of temperature changed to $10^{\circ} \mathrm{C} \times \mathrm{min}^{-1}$ up to $280^{\circ} \mathrm{C}$. After that, the temperature was kept constant for $10 \mathrm{~min}$.

The eluent from the column was transferred into the MS via transfer line $\left(280^{\circ} \mathrm{C}\right)$. As for the detection of analytes, the ionization was carried out by electron impact $(70 \mathrm{eV})$, and ions were analyzed with a single quadrupole in the SCAN or Selective Ion Monitoring (SIM) modes. Quadrupole temperature was set at $150^{\circ} \mathrm{C}$ and ion source at $250^{\circ} \mathrm{C}$.

The first mode of detection was used to confirm the identity of each of the analytes by comparing the experimental mass spectra with the mass spectra of the NIST 98 electronic library of the instrument. The latter was used to detect analytes at low concentrations by their characteristic ions. Three ions were selected for each analyte considering the experimental ion mass spectra recorded in the SCAN mode, as well as the ions reported in the literature for the determination of the analytes by GC/MS in the SIM mode. The criteria for qualitative analysis were the presence of SIM ions in the sample in addition to the agreement in the retention time of pesticides in sample and standard solutions. For quantitative purposes, the selected ions were those that had higher abundance and presented higher signal to noise ratio.

\section{Evaluation of analytical parameters}

The linear dynamic range was evaluated by the coefficient of determination $\left(\mathrm{R}^{2}\right)$ of the calibration curves with standard solutions at 5, 50, 200500 and $800 \mathrm{ng} \times \mathrm{mL}^{-1}$. The limit of quantification (LQ) was estimated by calculating the signal to noise ratio of a peak with a known concentration. The noise level was determined by evaluating the signal amplitude in regions immediately before or after the analyte peak signals by measuring the intensity of the noise from the highest to the lower apex of its signal. The limit of quantification (LOQ) was estimated as the analyte concentration that produces a peak signal ten times that of the background noise [23, 24].

Three independent samples of each fruit spiked with pesticides to give a final concentration of 50 and $500 \mu \mathrm{g} \times \mathrm{L}^{-1}$ in the QuEChERS extract were used to evaluate the accuracy and precision. The spiked samples were left to stand for 30 minutes before extraction to allow the pesticides to incorporate into the matrix. The accuracy was evaluated by the pesticide recovery and the precision was assessed by calculating the relative standard deviation (RSD).

\section{Field survey}

A short field survey was conducted with samples grown in the state of Yucatan Mexico. The fruit samples were collected in the following municipalities: 5 Dragon fruit from Kinchil, 5 melon from Buctzotz and 2 papaya from Dzilam González, 2 from Tizimín and 2 from Buctzotz. The collected fruits were processed to obtained composite samples from each municipality. Sugar apples were not included in the field survey since it was not harvest season at the time of the field study.

\section{Results and discussions}

\section{Chromatographic and detection conditions}

A mixture of 11 pesticides standard solution prepared in toluene in a concentration range from 5 to $800 \mathrm{ng} \times \mathrm{mL}^{-1}$ was separated using the chromatographic conditions indicated in the experimental section. Fig. 1 presents a GC/MS-SCAN chromatogram of the eleven pesticides. It was confirmed experimentally that the chromatographic conditions suggested by the Association of Official Analytical Chemists, [25], were the most appropriate for separation.

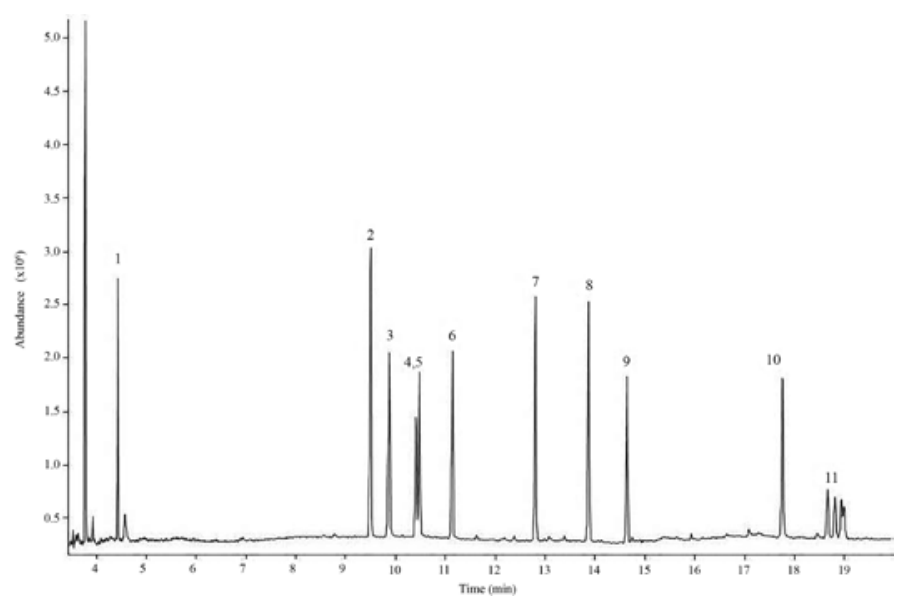

Fig. 1. GC/MS-SCAN chromatogram of pesticide standard solution (10 $\mu \mathrm{g} / \mathrm{g}$ ) prepared in toluene. Analytes: 1 dichlorvos, 2 diazinon, 3 chlorothalonil, 4 malaoxon, 5 parathionmethyl, 6 malathion, 7 endosulfan alpha, 8 endosulfan beta, 9 endosulfan sulphate, 10 coumaphos, 11 cypermethrine.

The ions for GC/MS-SIM were selected from the mass spectrum of each analyte obtained by running a standard solution of pesticides in SCAN mode, using the following criteria: greater abundance, greater specificity and less fragmentation. Selected ions mostly agreed with those reported in another work [3]. The pesticides investigated, the retention times and characteristic ions in this work are listed in Table 1. For the calibration curves, an extracted ion was selected using as criterion of selection those ions which gave higher signal to noise ratio, better selectivity and determination coefficient $\left(\mathrm{R}^{2}\right)$ closer to one. To construct the calibration curves of cypermethrin which presented several isomer peaks, the area of the second peak was used. 
Table 1. Pesticides of interest, retention times and characteristics ions.

\begin{tabular}{lcc}
\hline \multicolumn{1}{c}{ Pesticides } & $\mathbf{t}_{\mathbf{R}}, \mathbf{m i n}$ & Characteristics ions $\mathbf{~ m / z}$ \\
\hline 1 Dichlorvos & 4.48 & $79,109,185$ \\
2 Diazinon & 9.44 & $179,199,304$ \\
3 Chlorothalonil & 9.81 & $99,264,266$ \\
4 Malaoxon & 10.35 & $99,127,195$ \\
5 Parathion-methy & 10.43 & $109,125,263$ \\
6 Malathion & 11.07 & $125,158,173$ \\
7 - -endosulfan & 12.74 & $195,241,339$ \\
8 -endosulfan & 13.80 & $159,207,237$ \\
9 Endosulfan sulfate & 14.58 & $229,272,387$ \\
10 Coumaphos & 17.70 & $210,226,362$ \\
11 Cypermethrin & 18.64 & $163,181,207$ \\
\hline
\end{tabular}

\section{Matrix effect}

The matrix effect was evaluated carrying out calibrations curves of each pesticide in matrix phase and comparing them with calibration curve in toluene. It was observed that matrix effect presented a different behavior depending on the pesticide, the kind of matrix and the concentration (Fig 2).

In general, all the analytes in the fruit extracts presented an increase in chromatographic signal (positive matrix effect). This behavior is typical in GC analysis [26] and occurs when coextracted matrix components (waxes, pigments, lipids etc.) compete with analytes for the active sites in the liner protecting them from sorption or thermal degradation in the injector. Therefore, greater analyte amount be transferred to the column in the presence of matrix components than in neat solvent [27]. An overestimation of pesticide concentration in the fruit would result if the quantification were performed with a calibration curve in solvent phase as is showed in Fig 3a for diazinon. In particular, diazinon, malaoxon, malation, cypermethrin and coumaphos were listed by Poole [28] as typical compounds susceptible to matrix enhancement.

In contrast with Poole [28] who mentions that chlorothalonil is prone to matrix enhancement, this pesticide showed a decrease in the analytical signal (negative matrix effect) in dragon fruit extract (Fig 3b). The signal suppression is less common in GC analysis [26]. It occurs when non-volatile coextracted matrix components, accumulated into the gas chromatographic system, help to the generation of new active sites in the liner or in chromatographic column where pesticides can be sorbed or degradated [29]. In consequence, subestimations of pesticides are obtained if the quantification is carried out with a set of standard solutions prepared in toluene.
In addition, the matrix effect showed a dependence of pesticide concentration in papaya ( $\alpha$ endosulfan and $\beta$ endosulfan) and dragon fruit (diazinon) extracts as is showed in Fig 3c. Therefore, a overestimation (region i) or a subestimation (region ii) of pesticide concentration results if a calibration curve in solvent phase is used for quantification. Therefore, to minimize matrix effect the further work was carried out with a set of calibration solutions prepared with matrix blank extract.
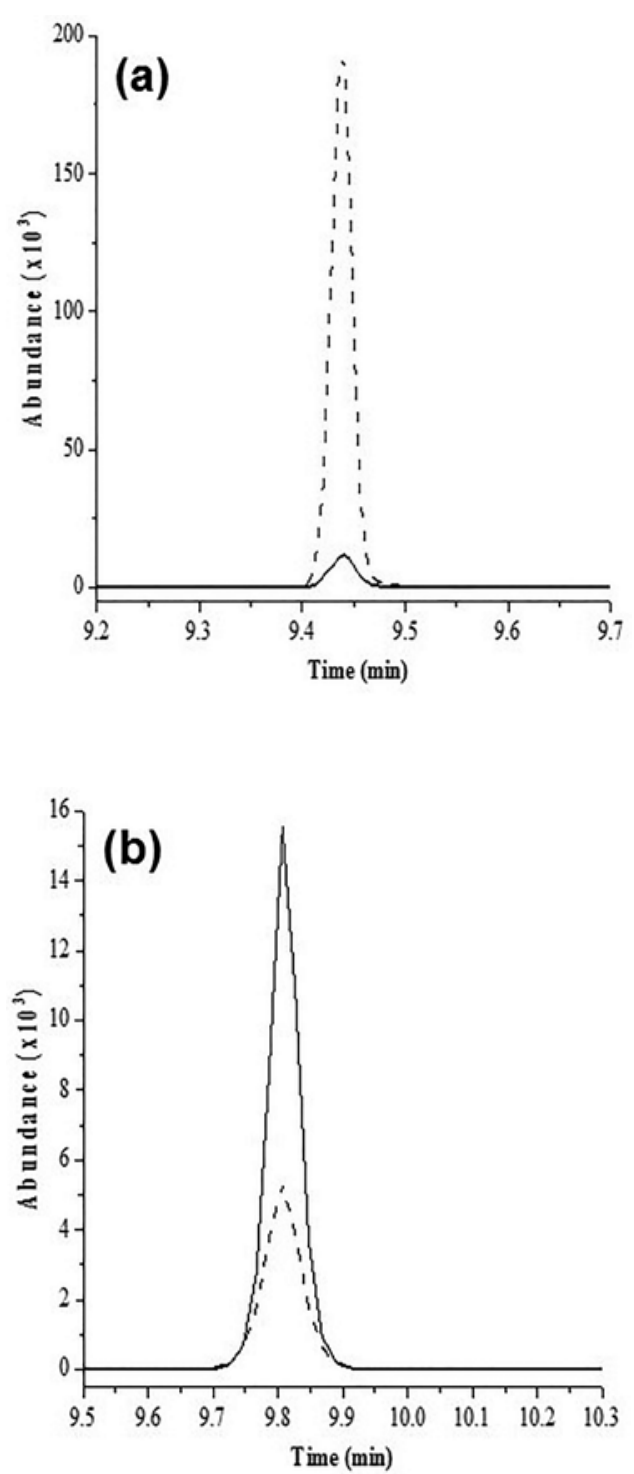

Fig. 2. GC/MS-SIM chromatograms of standard solutions $(800 \mathrm{ng} /$ $\mathrm{mL})$ prepared in toluene (-) and fruit extract (----). (a) Diazinon (m/z 304) diluted with melon extract showed a response enhancement and (b) chlorothalonil ( $\mathrm{m} / \mathrm{z} 264)$ dissolved with dragon fruit extract showed a response suppression. 

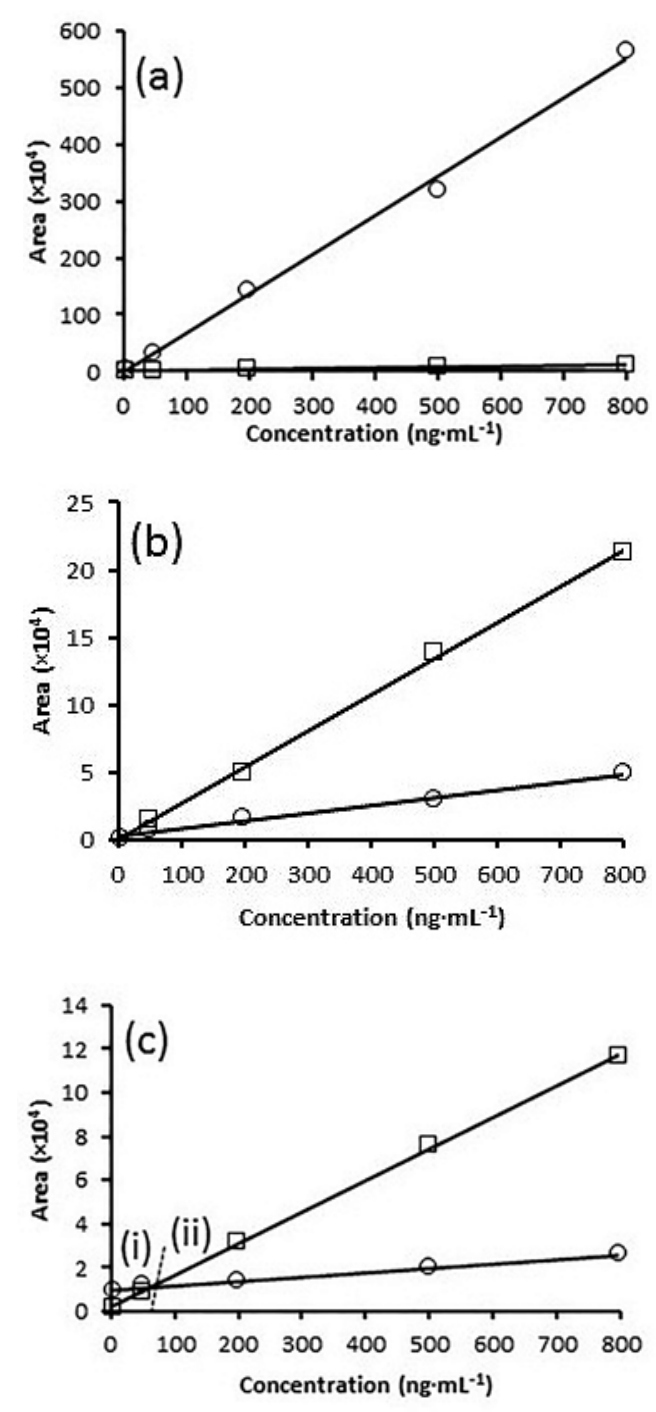

Fig. 3. Calibration curves prepared by dilution of pesticide standards with neat solvent $(\square)$ and matrix extract $(O)$ showing three kinds of matrix effect: positive for diazinon (m/z 304) in melon extract (a); negative for chlorothalonil (m/z 264) in dragon fruit extract (b); combined effect for diazinon (m/z 304) in dragon fruit extract (c).

\section{Evaluation of analytical parameters}

For method linearity evaluation, a stock solution of 20,000 $\mathrm{ng} \times \mathrm{mL}^{-1}$ was used to spike $15 \pm 0.1 \mathrm{~g}$ of free pesticide samples in order to obtain a final sample extract with pesticide concentration from 5 to $800 \mathrm{ng} \times \mathrm{mL}^{-1}$.

Calibration curves with determination coefficients greater than 0.99 were obtained for most pesticides in matrix phase; however, not all the analytes could be determined. It was possible with papaya, melon and sugar apple to obtain most of the calibration curves for all analytes under study, except for $\alpha$-endosulfan in melon. With the matrix of dragon fruit, it was possible to obtain calibration curves with determination coefficients greater than 0.995 for the pesticides: dichlorvos, diazinon, chlorothalonil, malathion, parathion-methyl, $\beta$-endosulfan, coumaphos, malaoxon and malathion. These values are consistent with those reported by Lacassie and coworkers [30] who reported determination coefficients between 0.995 and 0.999 for pesticides analysis including parathion-methyl and endosulfan using a multiresidue determination method for pesticides analysis in apples and pears by $\mathrm{GC} /$ MS based on a extraction procedure at $\mathrm{pH} 4.5$ with a mixture of acetone-dichloromethane-hexane (50:20:30, v/v/v).

Seventy nine percent of the limits of quantification (Table 2),

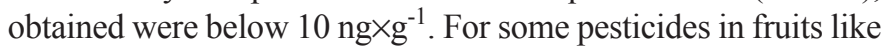
papaya, this value is the lowest maximum residue limit (MRL) set in the EU pesticide data base [31]. In sugar apple the LOQs of malaoxon, malation, and parathion-methyl were 14.71, 16.67, $31.25 \mu \mathrm{g} \times \mathrm{Kg}^{-1}$, respectively which were similar to data reported internationally [21, 22]. Fourteen percent of the pesticides could not be determined possible due to matrix effect.

Table 2. Limits of quantification $\left(\mathrm{ng} \times \mathrm{g}^{-1}\right)$ for the eleven pesticides obtained in analyzed fruits.

\begin{tabular}{lcccc}
\hline \multirow{2}{*}{ Pesticides } & \multicolumn{4}{c}{ Limits of quantification } \\
\cline { 2 - 5 } & Papaya & Melon & $\begin{array}{c}\text { Sugar } \\
\text { apple }\end{array}$ & $\begin{array}{c}\text { Dragon } \\
\text { fruit }\end{array}$ \\
\hline Dichlorvos & 4.85 & 1.97 & 3.55 & 0.82 \\
Diazinon & 3.27 & 2.16 & 5.49 & 3.50 \\
Chlorothalonil & 2.86 & 2.78 & 2.48 & 2.07 \\
Malaoxon & 4.00 & 4.00 & 14.71 & ND \\
Parathion-methyl & 2.19 & 1.95 & 31.25 & ND \\
Malathion & 5.56 & 5.56 & 16.67 & 1.39 \\
$\alpha$-endosulfan & 2.84 & ND & 2.30 & 4.50 \\
$\beta$-endosulfan & 9.09 & 1.76 & 0.28 & 2.39 \\
Endosulfan sulfate & 4.00 & 1.66 & 3.50 & ND \\
Coumaphos & 2.89 & 2.73 & 9.09 & ND \\
Cypermethrin & 4.76 & 5.05 & 0.92 & ND \\
\hline
\end{tabular}

ND: Not Detected

Most of these values were below or at nearby concentrations of the standard of lower concentration of the dynamic ranges used for evaluating pesticides in the samples. The limits of quantification achieved were suitable for quantification of pesticides in fruit samples according to international standards. For the evaluation of the accuracy and precision of the method, samples, free from the analytes evaluated, were spiked in triplicate at two levels, to give a final concentration of 12.5 and $125 \mathrm{ng} \times \mathrm{g}^{-1}$ at the end of the QuECHERS method. AOAC establishes that the accuracy should be between 70 and $120 \%$ and the precision less than 15\% [7]. Besides, the guideline, Acceptability Criteria of Process Control and Fortification Recoveries, established by the Agricultural Marketing Service in 2003 expand the acceptable range for recovery to $50-150 \%$ and the relative standard deviation to $20 \%$.

The $93 \%$ of the recoveries obtained for both spiked levels were within the range established by the AOAC in 2007 (Table 3). Recoveries higher than $120 \%$ for $\alpha$-endosulfan, dichlorvos and coumaphos were obtained in papaya and dragon fruit. How- 
Table 3. Average percentage recoveries and precision (\%RSD) obtained from spiked papaya, melon, sugar apple and dragon fruit at two concentrations $\left(\mathrm{ng} \times \mathrm{g}^{-1}\right)$.

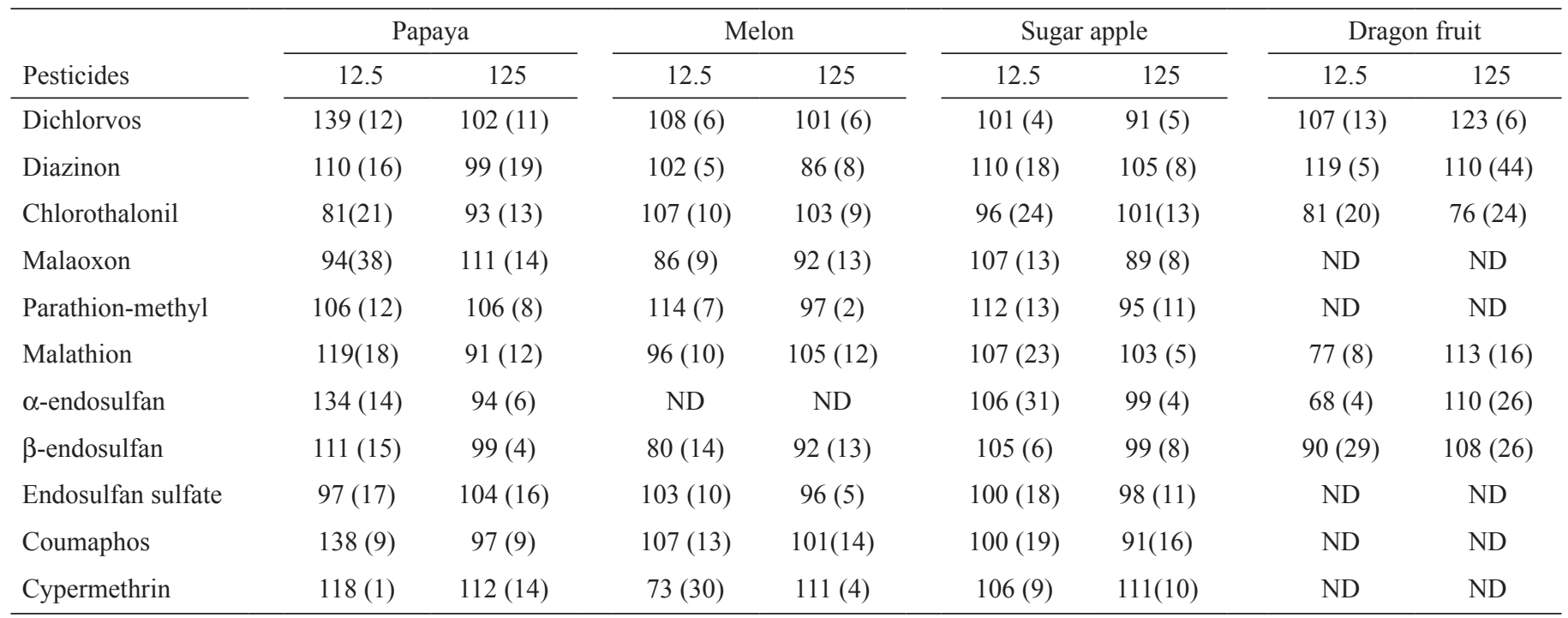

ND: Not Detected

ever, recoveries of these pesticides were within the range established by the United States Department of Agriculture [32].

The precision of the method, evaluated as the relative standard deviation of the pesticides, depended on the analyte and matrix. The $71 \%$ of RSD values for both spiked levels were below of $15 \%$ established by the AOAC (2007) and $84 \%$ of the RSD values satisfied the guidelines established $(\mathrm{RSD} \leq 20 \%)$ by the United States Department of Agriculture [32] and the European Union [33]. In both cases, chlorothalonil in dragon fruit, papaya and sugar apple and $\alpha$-endosulfan and $\beta$-endosulfan in dragon fruit and sugar apple showed RSDs higher than 20\%. Only cypermethrin presented an RSD value higher than $20 \%$ in melon.

\section{Analysis of samples}

Papaya composite samples from Buctzotz, Dzilam Gonzalez and Tizimín, revealed the presence of parathion-methyl and malathion. Composite samples from Buctzotz and Dzilam Gonzalez also presented malaoxon. The melon composite sample from Buctzotz presented the previous three pesticides (Table 4).

The values of the pesticide concentrations in papaya and melon sample aliquots analyzed in this study were above the quantification limits. However, the concentrations of the pesticides determined in the fruits were lower than the maximum residue levels $\left(10 \mu \mathrm{g} \times \mathrm{kg}^{-1}\right)$ established by the European Union [33] for vegetables and fruits.

Our results differ with the study made by Hjorth and coworkers [34] in South America, who reported the presence of the pesticides acetamiprid, acephate, methamidophos, and thiabendazole in melon and Chlorothalonil, Dimethoate, Dithiocarbamates, Thiacloprid, Methomyl in papaya above the maximum residue levels of European Union directives. Nevertheless, Camino-Sánchez and coworkers [35], reported that the positive presence of contaminated melon samples, with Azoxystrobin, Bifenthrin, Buprofezin, and the sum of triadimefon and triadimenol, was higher than $30 \%$ but according to the results presented, the values were not higher than the MRLs accepted in Europe.

In dragon fruit samples from Kinchil was possible to identify the presence of the pesticide parathion-methyl. However, as the calibration curve in matrix phase for this pesticide could not be obtained, it was not possible to quantify it. The presence of interfering components, the $\mathrm{pH}$ of the extract and an accelerated degradation rate could be the responsible factors that avoid the determination. Anastassiades and Lehotay reported [5] that

Table 4. Average concentrations $\left(\mathrm{ng} \times \mathrm{g}^{-1}\right)$ in papaya and melon samples with allowed maximum residue levels, MRLs (ng $\left.\times \mathrm{g}^{-1}\right)$

\begin{tabular}{|c|c|c|c|c|c|}
\hline \multirow[b]{2}{*}{ Pesticide } & \multicolumn{3}{|c|}{ Papaya } & \multirow{2}{*}{$\begin{array}{c}\text { Melon } \\
\text { Buctzotz }\end{array}$} & \multirow{2}{*}{ MRLs } \\
\hline & Buctzotz & Dzilam & Tizimín & & \\
\hline Malaoxon & 1.74 & 1.92 & ND & 5.97 & $20 *$ \\
\hline Parathion-methyl & 1.02 & 1.58 & 5.20 & 6.41 & 10 \\
\hline Malathion & 7.56 & 3.57 & 2.80 & 2.93 & $20 *$ \\
\hline
\end{tabular}

${ }^{2}$ European Union.

*Addition of malathion and malaoxon expressed as malathion.

ND: Not Detected 
not only the $\mathrm{pH}$ can have a strong influence on the recoveries of basic or acidic pesticides as well as in the degradation rate of certain compounds, but also the presence of co-extractive matrix components.

Even though sugar apple was not analyzed, calibration and recovery results show that QuEChERS method is suitable for analysis of pesticides present on that fruit.

The above results make it possible to carry out tests for routine quality control of samples of papaya, melon, sugar apple and dragon fruit in which their safety is evaluated with respect to the presence of pesticides included in this study.

\section{Conclusions}

i) The evaluation of the analytical parameters supported the method for the quantification of pesticides in samples of papaya, melon, dragon fruit, and sugar apple from the state of Yucatan, Mexico in a quick and environmental friendly manner. It was found out the presence of some pesticides in the pilot sampling of dragon fruit, papaya and melon, with concentrations below the permissible limits for their consumption. This paper extends the application of QuEChERS method to dragon fruit and sugar apple of recognized taste and exotic character.

\section{Acknowledgements}

This research has been supported by Programa de Impulso y Orientacion a la Investigacion 2009 (PRIORI), Universidad Autonoma de Yucatan, Mexico. Project SISTPROY:FIQI-2010-0008 .

\section{References}

1. Díez, C., Traag, W. A., Zommer, P., Marinero, P., Atienza, J. J. Chromatogr. A. 2006, 1131, 11-23.

2. Ortelli, D., Edder, P., Corvi, C. Anal. Chim. Acta. 2004, 520, 33-45.

3. Mol, H.G.J., Rooseboom, A., van Dam, R., Roding, M., Arondeus, K., Sunarto, S. Anal Bioanal Chem. 2007, 389, 1715-1754.

4. Arrebola, F.J., Martinez-Vidal, J. L., Mateu-Sanches, M., Álvarez-Castellón F. J. Anal. Chim. Acta 2003, 484, 167-180.

5. Anastassiades, M., Lehotay, S. J. AOAC Int. 2003, 86, 412-43.

6. Gonzales-Curbelo, M. A., Socas-Rodríguez, B., Herrera-Herrera, A. V., Gonzales-Sálamo, J., Hernández-Borges, J. \& Rodríguez-Delgado, M. A. Trends Anal. Chem. 2015, 71, 169-185.

7. Lehotay, S., Maótovská, K. J. AOAC Int. 2005, 88, 630-638.

8. Lehotay, S.J., Son, K. A., Kwon, H., Koesukwiwat, U. Fu, W., Mastovska, K., Hoh, E., Leepipatpiboon, N. J. Chromatogr. A. 2010, 1217, 2548-2560.

9. Wilkowska, A., Biziuk, M. Food Chem. 2011, 125, 803-812.

10. Cieślik, E., Sadowska-Rociek, A., Molina-Ruis, J.M., Surma-Zadora, M. Food Chem. 2011, 125, 773-178.
11. Amelin, V.G., Lavrukhin D.K., Tretýakov, A.U. J. Anal. Chem. 2013, 68, 912-923.

12. Bakirci, G. T., Yaman-Acay, D. B., Bakirci, F., Otles, S. Food Chem. 2014, 160, 379-392.

13. Rajski, L., Gómez-Ramos M. M., Fernández-Alba, A. R. J. Chromatogr. A. 2014, 1360, 119-127.

14. Wang, J., Chow, W., Chang, J., Wong j. W. J. Agricultural Food Chem. 2014, 62, 10375-10391.

15. Alvarado, J., González, R. L., Cobos, V. M. Ciencia y desarrollo 1997, 23, 51-57.

16. Moguel-Mena, J.A. Infocampo-Gaceta rural de Yucatán 2009, 3, 15.

17. Cobos, V. M., Mora, M. A. Revista de Toxicología 2006, 23, 17-23.

18. Liu, M., Hashi, Y., Song, Y., Lin, J. M. J. Chromatogr. A. 2005, 1097, 183-187.

19. Mezcua, M., Martnez-Uros, A, M.,Wylie P.L., Fernández-Alba, A.R. J. AOAC Int. 2009, 92, 1790-1806.

20. Diniz-Madureira, F., da Silva-Oliveira, F.A., Robert de Souza, W., Pontelo, A. P., Goncalves de Oliveira, M. L., Silva, G. Food Addit. Contam. 2012, 29, 665-678.

21. Da Silva-Sousa, J., Carius, de Castrom, R., Albuquerque-Andrade, A., Gomes-Lima, C., Lima, L. K., Liberato-Milhome, M.A., Ferreira do Nascimento, R. Food Chem. 2013, 141, 2675-2681.

22. Payá, P., Anastassiades, M., Mack, D., Sigalova, I., Tasdelen, B., Oliva, J., Barba, A. Anal Bioanal Chem. 2007, 389, 1697-1714.

23. Cherta, L., Beltran, J., López, F., Hernández, F. Food Anal. Met. 2013, 6, 1170-1187.

24. Kromidas, S. HPLC made to measure: a practical handbook for optimization. Wiley- VCH, 2006.

25. Association of Official Analytical Chemist. Official Method of Analysis of the Association of Official Analytical Chemists. Horwitz, W., \& Latimer, G. W. (Eds). (18th ed). (ch 10, pp 17-26). Gaithersburg, MD, USA: AOAC International. 2007.

26. Costa, F.P., Souza-Caldas, S., Prime, E.G. Food Chem. 2014, 165, 587-593.

27. Hajšlová, J., Zrostlíková, J. J. Chromatogr. A. 2003, 1000, 181-197.

28. Poole, C.F. J. Chromatogr. A. 2007, 1158, 241-250.

29. Aparecida de Sousa, F., Guido-Costa, A.I., Lopez -Ribeiro de Queiroz M.E., Teófilo R.F., Agusto-Neves A., Paqulino de Pinho, G. Food Chem. 2012, 135, 179-195.

30. Lacassie, E., Dreyfuss, M.F., Daguet, J.L., Vignaud, M., Marquet, P., Lachậtre, G. J. Chromatogr. A. 1998, 805, 319-326.

31. Pesticide, EU- MRLs. Consulted on 23 December 2014. URL. http://ec.europa.eu/sanco_pesticides/public/?event=homepage \&language $=\mathrm{EN}$

32. United States Department of Agriculture. Agricultural Marketing Service (2011). URL http://www.ams.usda.gov/AMSv1.0/farmersmarkets

33. Commission Regulation (EC) 396/2005 of the European Parliament and of the Council of 23 February 2005 on maximum residue levels of pesticides in or on food and feed of plant and animal origin and amending Council Directive 91/414/EEC. 2005R0396EN-10.04.2008-002.001,246.

34. Hjorth, K., Johansen, K., Holen, B., Andersson, A., Christensen, H.B., Siivinen, K., \& Toome, M.. Food Control. 2011, 22, 1701-1706.

35. Camino-Sánchez, F. J., Zafra-Gómez, A., Ruiz-Garcá, J., Bermúdez-Peinado, R., Ballesteros, O., Navalon, A., Vílchez J. L. J. Food Compos. Anal. 2011, 24, 427-440. 